\title{
Memoriam: Jack P. Strong, MD
}

\author{
Fred H. Rodriguez Jr. ${ }^{1}$
}

Received: 5 December 2019 / Accepted: 5 December 2019 / Published online: 13 January 2020

(c) United States \& Canadian Academy of Pathology 2020

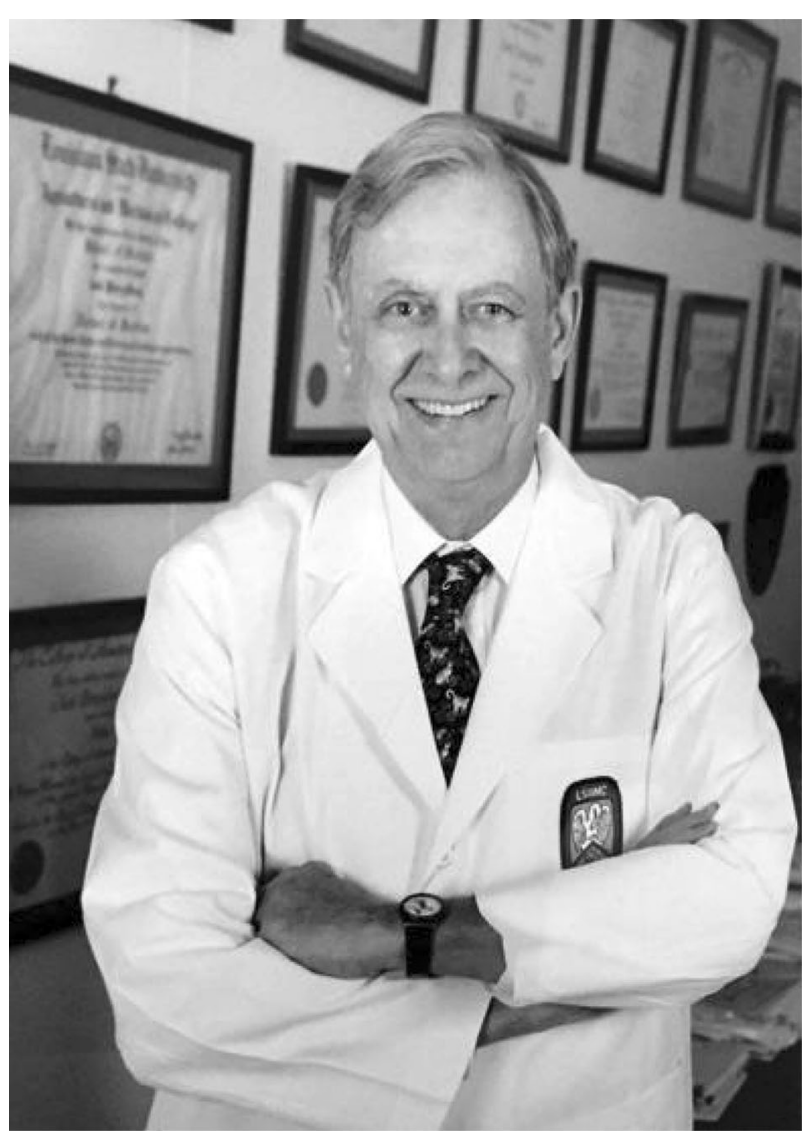

"Dr. Jack Strong (1980)—-the first LSU Health Sciences Center faculty member to be named a Boyd Professor, in his office at the LSU School of Medicine Department of Pathology, New Orleans, LA. From the LSU Department of Pathology archives

Fred H. Rodriguez

frodri@1suhsc.edu

1 Department of Pathology, Louisiana State University School of Medicine, 1901 Perdido Street, New Orleans, LA 70112, USA
It is with heartfelt sadness that we announce the passing of Dr. Jack P. Strong, past Head of the Department of Pathology at the Louisiana State University (LSU) School of Medicine on October 19, 2019. He was 91 years old.

Dr. Strong was a teacher, clinician, and researcher who will be remembered for his great contributions to the world of pathology both nationally and abroad. He held the first Boyd Professorship awarded to an LSU School of Medicine faculty member-the highest academic honor in the LSU system. He was Head of the Department of Pathology at LSU Health Sciences Center for over 40 years where his boundless enthusiasm and professionalism influenced countless medical students, residents and graduate students to enter the field of pathology.

Dr. Strong was a leader in the US-Canadian Academy of Pathology (USCAP), having served and guided the Academy for over fifty years in positions ranging from a Council Member to President. He was the recipient of both the F.K. Mostofi Distinguished Service Award and the US-Canadian Academy of Pathology President's Award. He was respected internationally and served as both Treasurer and President of the International Academy of Pathology (IAP). A dynamic researcher, he was the first scientist to establish that smoking can cause heart disease and that smoking can cause the formation of cholesterol plaques on artery walls.

He was an inspirational leader who motivated people, through his support and encouragement to accomplish things they would never have thought to accomplish on their own. Dr. Strong was known for his open door and would always make time to listen and discuss courses of action. One would leave his office with a little more confidence to continue, and with the affirmation that he was always there to help to "cover your back".

Dr. Strong has left an enduring legacy to the IAP, USCAP, the LSU School of Medicine, and the entire profession of Pathology, and Medicine in general. He will be greatly missed.

(This memoriam was originally published in Laboratory Investigation.) 